\title{
DYNAMIC ANALYSIS OF A ROLLING BEARING CAGE WITH RESPECT TO THE ELASTIC PROPERTIES OF THE CAGE FOR THE AXIAL AND RADIAL LOAD CASES
}

The aim of this paper is to detail the creation of a large tapered roller bearing model with flexible body cages in the Adams program suite for subsequent dynamic analysis and to obtain information about kinematic and dynamic relationships of steel and plastic cages under various operating conditions. The bearing model was made to closely resemble its real-life counterpart, which allows us to estimate load conditions, dynamic conditions of individual bearing parts and interactions between them.

Keywords: Rolling bearing, flexible body, cage, Adams, dynamic.

\section{Introduction}

This article details the creation of a virtual bearing model allowing the analysis of individual bearing components under dynamic behavior. Although inner and outer bearing rings and rollers are defined as solid materials, the bearing cage models also take into account elastic properties thereof. Chapter 2 details the creation of the said models. Two models of tapered roller bearings will be considered: one with steel cage and the other with plastic cage.
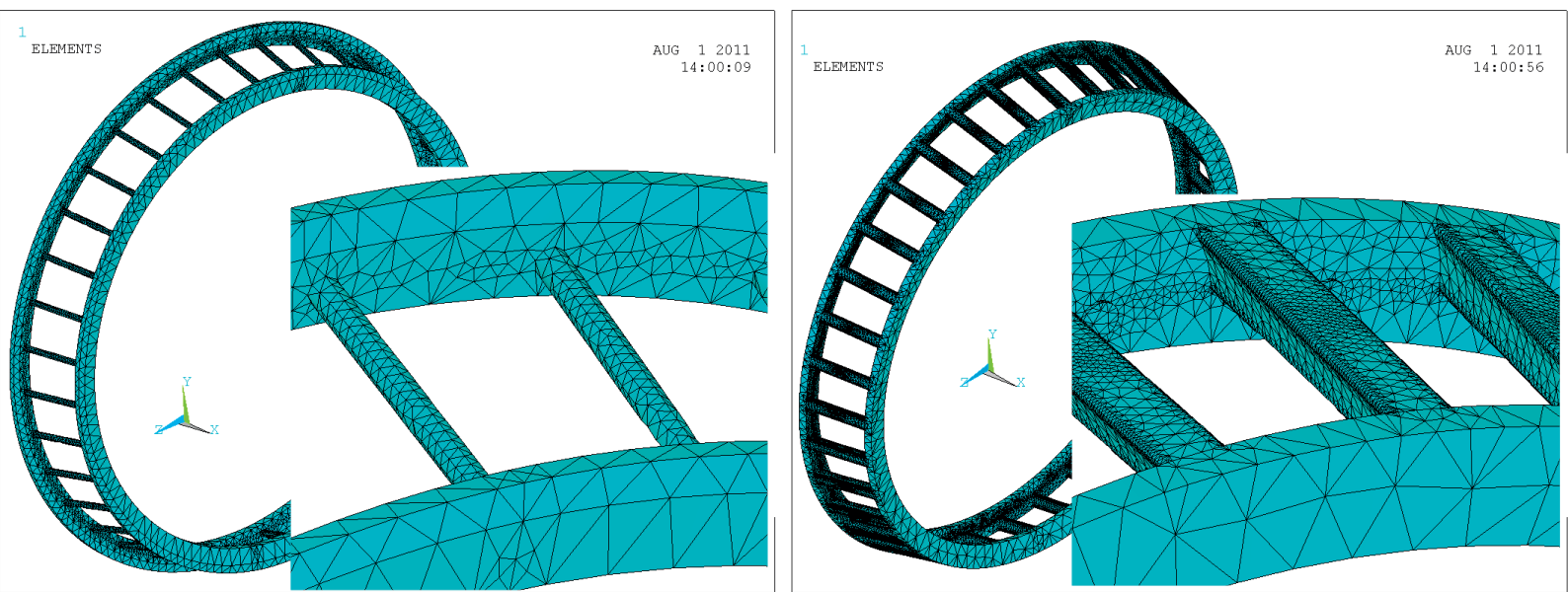

Fig. 1 Finite-element mesh of steel (left) and plastic (right) cage in Ansys program

\footnotetext{
* Robert Kohar, Slavomir Hrcek

Department of Design and Machine Elements, Faculty of Mechanical Engineering, University of Zilina, Slovakia

E-mail: robert.kohar@fstroj.uniza.sk
} 
The actual MNF file can be created in various FE programs such as Nastran, Ansys or Abaqus [5], [6] and [7].

The flexible cage model was created in FE software Ansys which contains a built-in macro for this purpose. The first step consisted of finite-element mesh creation along with the definition of material properties (Fig. 1, Table 1) [8] and [9].

Material properties of steel and plastic cage

Table 1

\begin{tabular}{|c|c|c|c|c|c|}
\hline & $\begin{array}{c}\text { Density } \\
{[\mathrm{kg} .} \\
\left.\mathrm{mm}^{-3}\right]\end{array}$ & $\begin{array}{c}\text { Young } \\
\text { modulus } \\
{[\mathrm{MPa}]}\end{array}$ & $\begin{array}{c}\text { Poisson } \\
\text { constant } \\
{[-]}\end{array}$ & $\begin{array}{c}\text { Element } \\
\text { type }\end{array}$ & $\begin{array}{c}\text { Number } \\
\text { of } \\
\text { elements }\end{array}$ \\
\hline Steel cage & $7.85 .10^{-6}$ & $2.02 .10^{5}$ & 0.29 & $\begin{array}{c}\text { Solid } \\
187\end{array}$ & 39105 \\
\hline $\begin{array}{c}\text { Plastic } \\
\text { cage }\end{array}$ & $1.1 .10^{-6}$ & 3000 & 0.42 & $\begin{array}{c}\text { Solid } \\
187\end{array}$ & 259694 \\
\hline
\end{tabular}

After generation of the finite-element mesh and material definition a macro is executed, creating the MNF file which requires the following user input: System of Model Units, Eigenmodes, Element Results, Shell Element Result Output Control, Filename, Solve and create export file to ADAMS.

MNF file analysis and further modification thereof is possible using the MD Adams/Flex Toolkit. The "MNF-MNF Optimizer" was used to analyze and reduce the complexity of the cage models by removing Internal Solid Element Geometry. An alternative approach is to apply the Mesh Coarsening Algorithm, resulting in reduced element counts and increased calculation speed. However, the mentioned approach also modifies node coordinates, which would invalidate load simulations obtained by dynamic simulations for further analysis in FE programs and was thus not used [10].

The next step after applying the above process consists of integration of "flex body" within MSC.Adams/View modeler. Figure 2 shows the flexible model integration algorithm within the dynamic simulation.

Dynamic simulation results - axial load force $F_{a}=518 \mathrm{kN}$ with rotational speed $n=15.5 \mathrm{rPM}$

Dynamic simulation results with axial load force and rotational speed $\mathrm{n}=15.5 \mathrm{rPM}$ represent force interactions between individual bearing parts, movement of bearing cage center of gravity and angular velocity thereof.

Figure 3 shows a comparison of load distribution of individual rollers with theoretical calculations based on [11] and [12], wherein element load $\mathrm{Q}_{\max }=56568 \mathrm{~N}$. Results of the dynamic simulation were obtained in time $\mathrm{t}=10$ seconds.

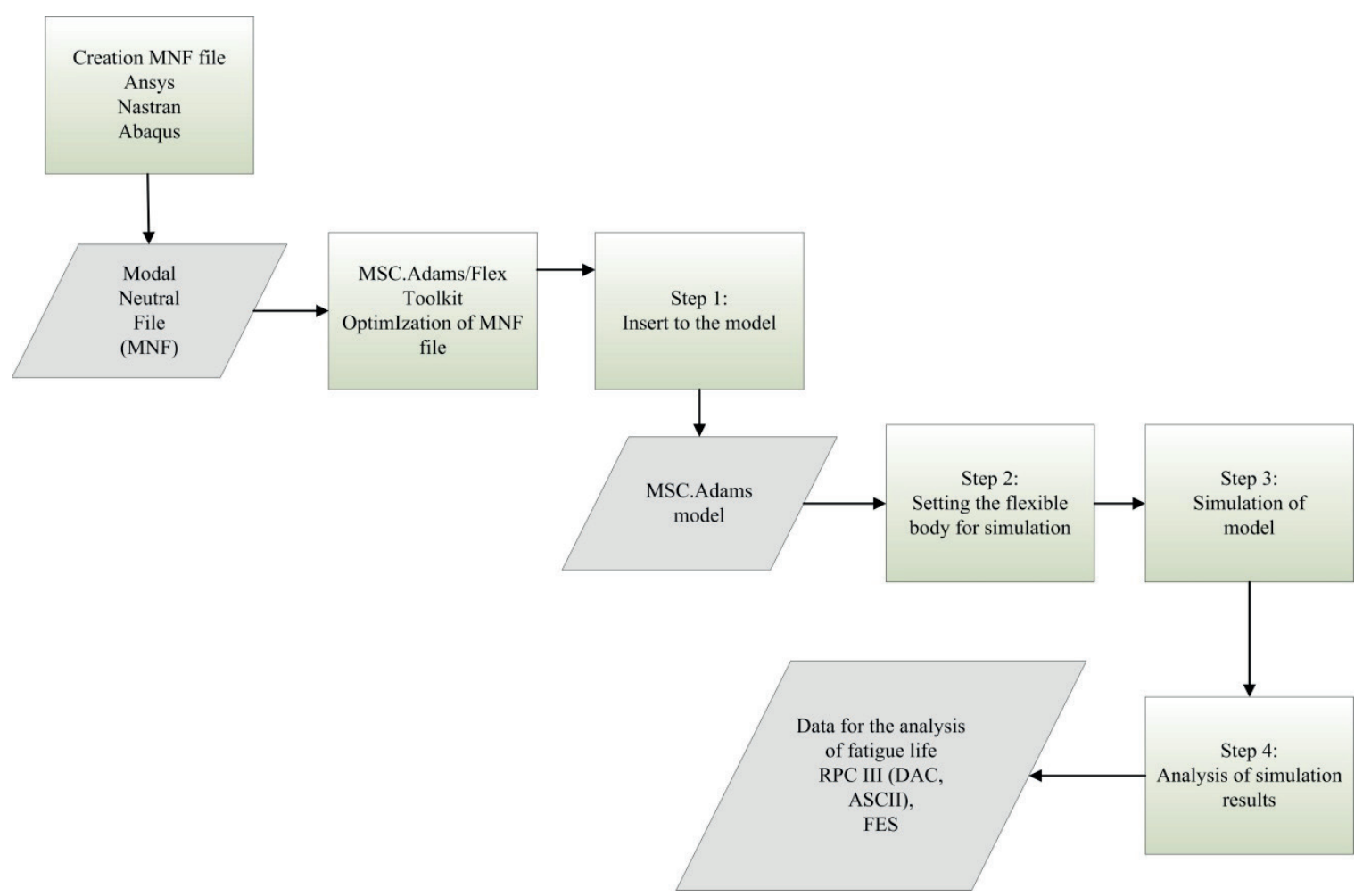

Fig. 2 "Flexible body" integration algorithm within the dynamic simulation 


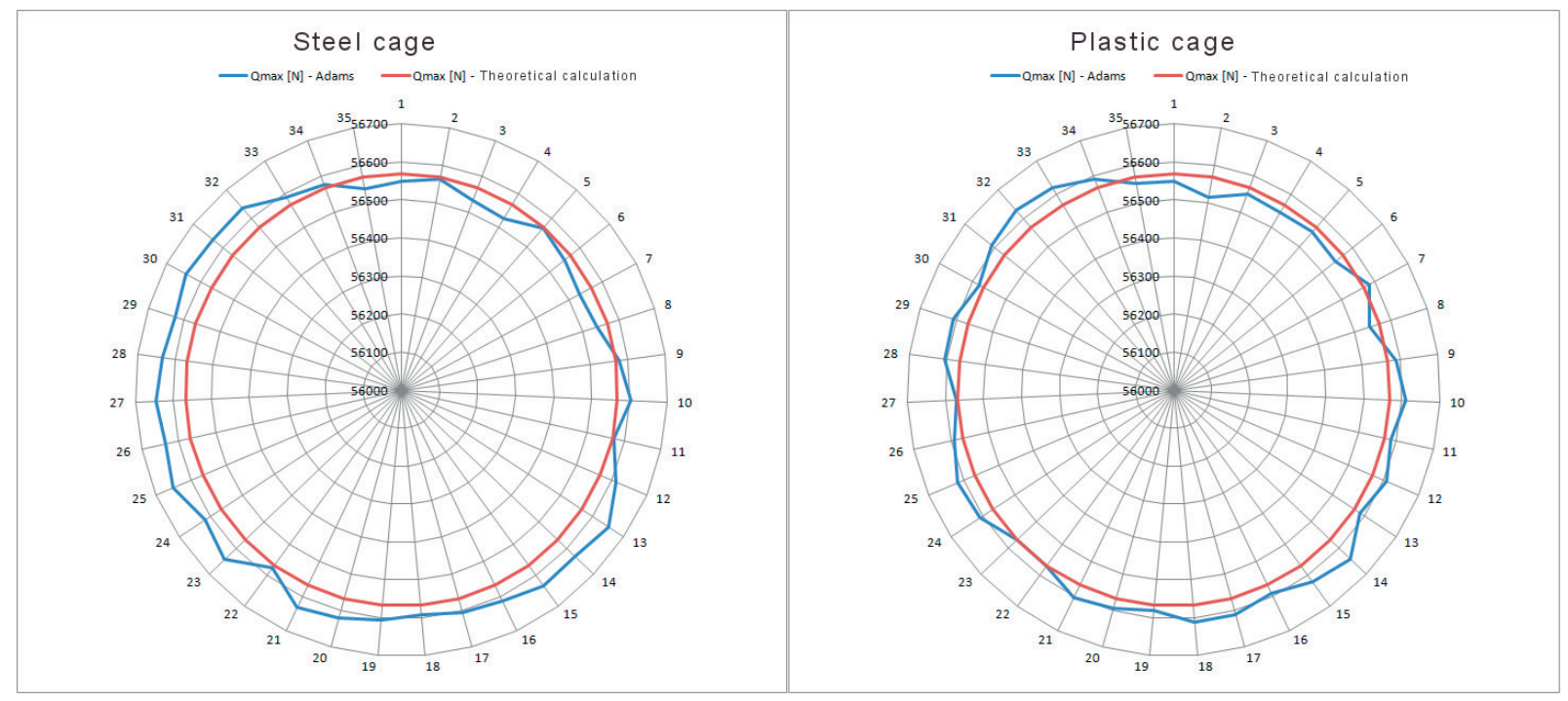

Fig. 3 Load distribution of individual elements compared with theoretical calculations

Figure 4 shows forces between roller and cage, roller and inner ring and angular velocity of this roller. Maximum force between steel cage and rollers was observed during interaction of the cage with roller $n .22$ and is equal to $686 \mathrm{~N}$ (Fig. 4 up, green line). Also shown is the force between inner ring and roller n. 22 (red line) which varied between $54023 \mathrm{~N}$ and $58593 \mathrm{~N}$. The blue line displays angular velocity of roller n. 22 and varies between $484^{\circ} / \mathrm{s}$ and $495^{\circ} / \mathrm{s}$.
Maximum force between plastic cage and rollers was observed during interaction of the cage with roller n. 24 and is equal to $301 \mathrm{~N}$ (Fig. 4 down, green line). Also shown is the force between inner ring and roller n. 24 (red line) which varied between 54273 $\mathrm{N}$ and $58571 \mathrm{~N}$. The blue line displays angular velocity of roller n. 24 and varies between $485^{\circ} / \mathrm{s}$ and $494^{\circ} / \mathrm{s}$, similar to the velocity observed for the steel cage.

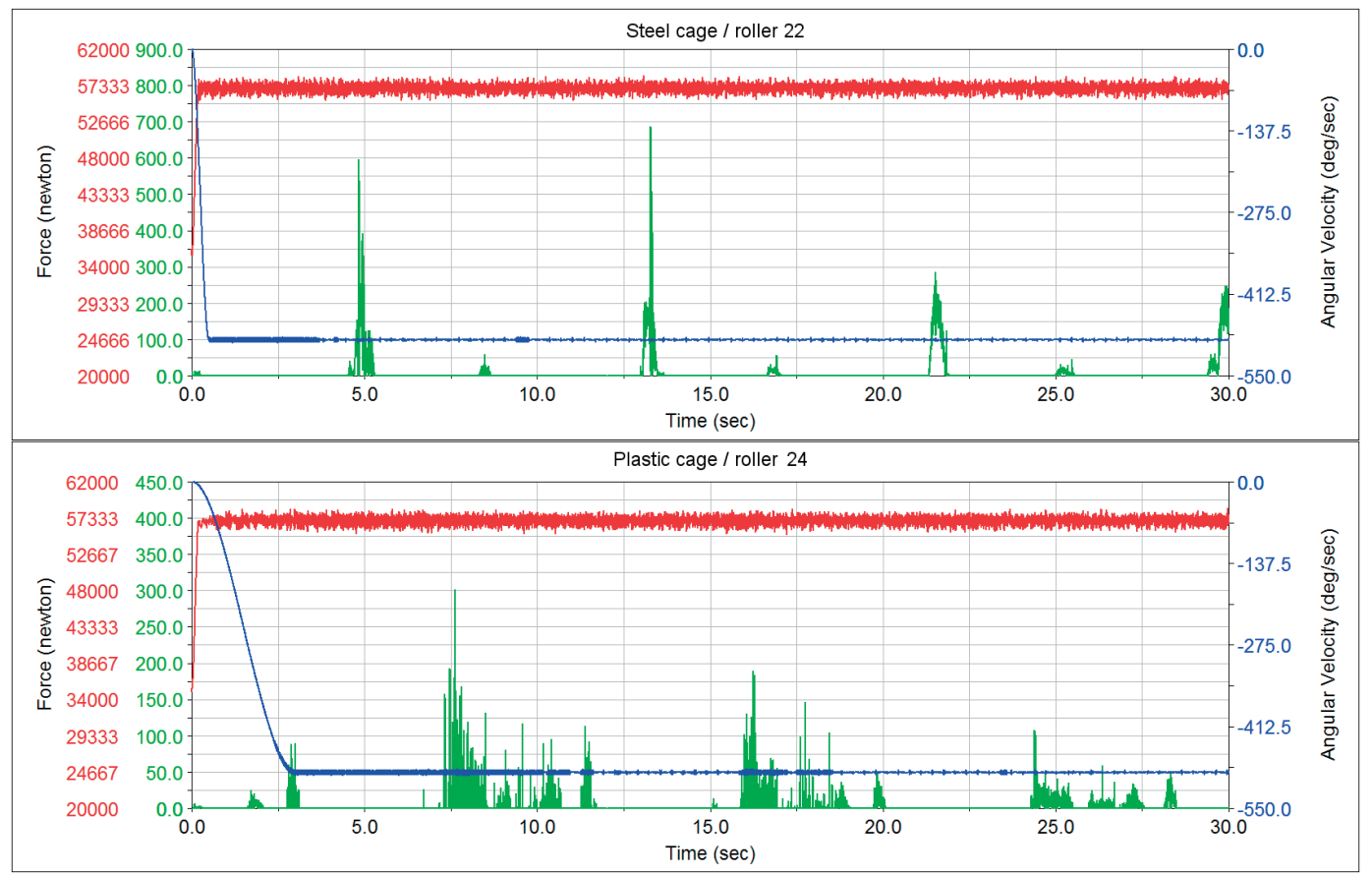

Fig. 4 Force interaction between inner ring and rollers (red lines), force interaction between cage and rollers (green lines) and angular velocity of rollers. 

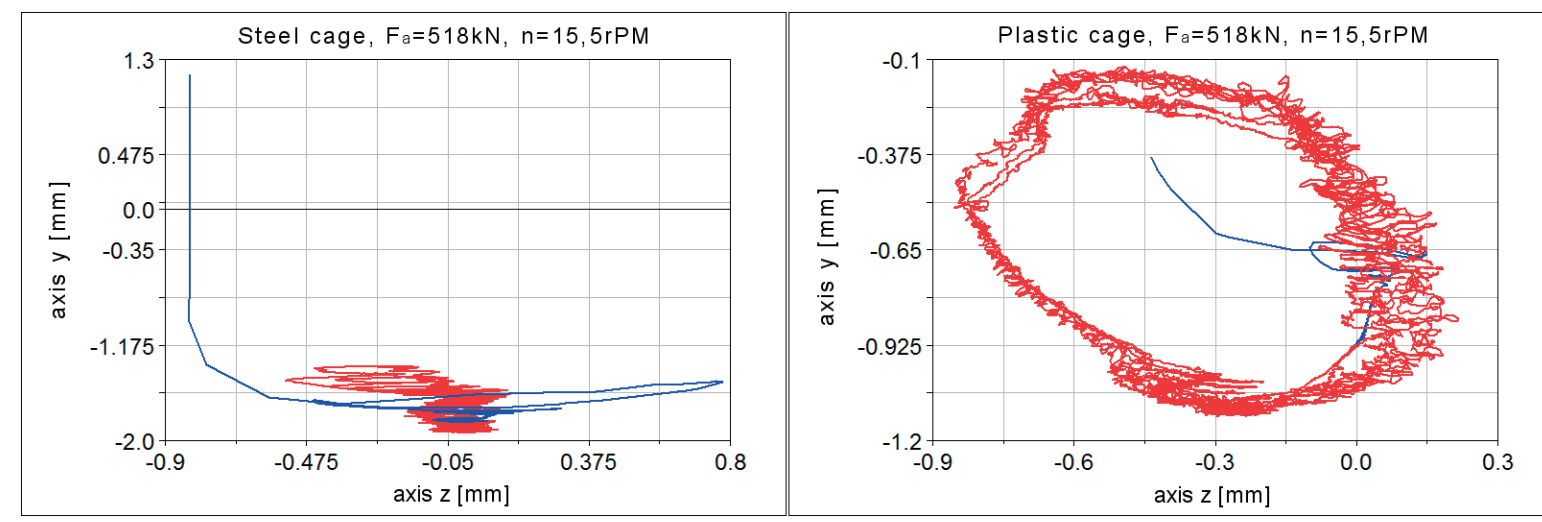

Fig. 5 Movement of center of gravity of steel cage (left side) and plastic cage (right side) in the $y$-z plane under axial load
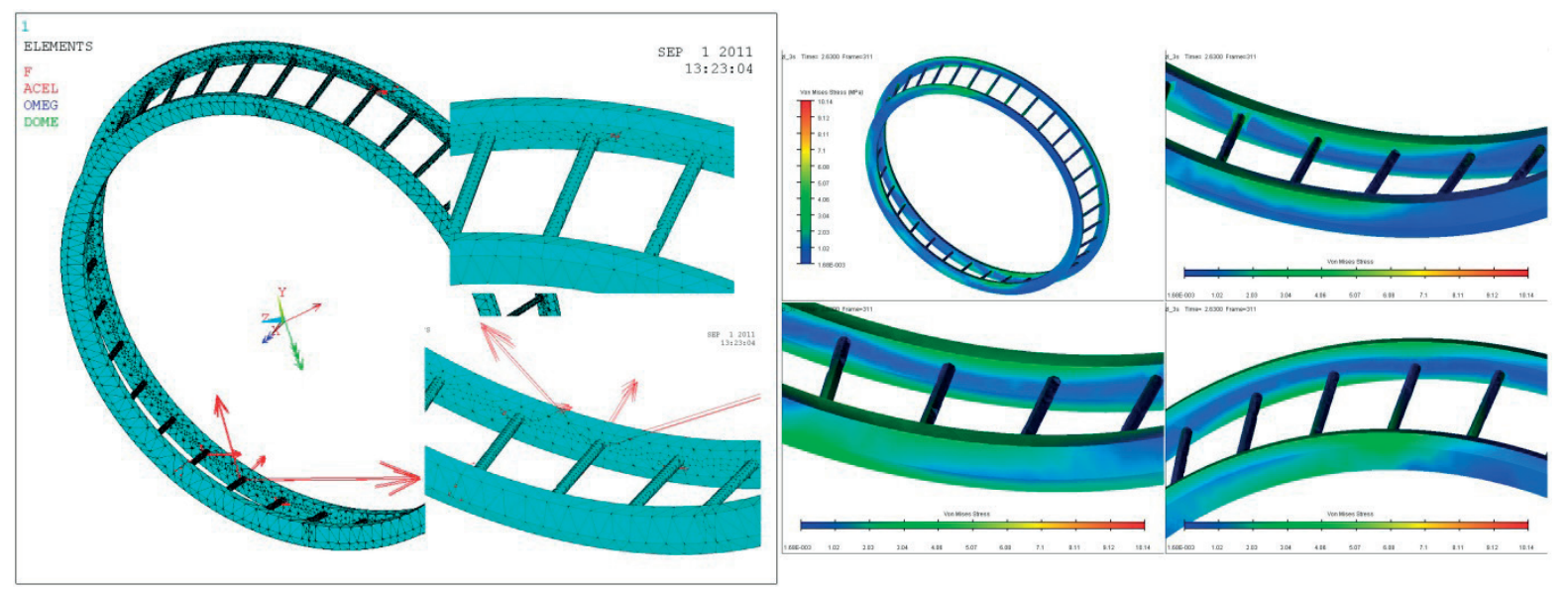

Fig. 6 Force interaction between steel cage and rollers (left side) and maximum von Mises stress of steel cage

Figure 5 shows the center of gravity location in the y-z plane of steel and plastic cage. Fig. 6 shows force interaction between inner ring and rollers and the von Mises stress of steel cage and Fig. 7 shows force interaction between inner ring and rollers and the von Mises stress of plastic cage.

Analysis of dynamic simulation results shows the steel cage is in contact with rollers in lower and upper parts of the bearing, with forces in the upper bearing parts reaching up to $700 \mathrm{~N}$ at cage guides and $100 \mathrm{~N}$ at lower parts, also at cage guides. Maximum von Mises stress of $10 \mathrm{MPa}$ was recorded in time $\mathrm{t}=2.63 \mathrm{~s}$ (Fig. 6).

Dynamic simulation of plastic cage bearing shows similar results to those presented above. The plastic cage is in contact with rollers in lower and upper parts of the bearing. Forces in the lower part of the bearing reach up to $300 \mathrm{~N}$ at cage guides and up to $50 \mathrm{~N}$ at upper parts of the bearing cage guide surfaces. Maximum von Mises stress of $0.6 \mathrm{MPa}$ was recorded in time $\mathrm{t}=$ $16.8 \mathrm{~s}$ (Fig. 7).

Dynamic simulation results - radial load force $\mathrm{F}_{\mathrm{r}}=4500 \mathrm{kN}$ with rotational speed $\mathrm{n}=15.5 \mathrm{rPM}$
Similar to axial load force, we calculated force interactions between individual bearing parts, movement of bearing cage and angular velocity thereof when subjected to radial force.

Figure 8 shows a comparison of load distribution of individual rollers with theoretical calculations based on [3], wherein element load $\mathrm{Q}_{\max }=56499 \mathrm{~N}$. Results of the dynamic simulation were obtained in time $\mathrm{t}=10$ seconds.

Figure 9 shows force between roller and cage, roller and inner ring and angular velocity of the roller. Also shown is the force between inner ring and roller n. 13 (red line). Maximum force between steel cage and rollers was observed for roller n. 13 and is equal to $800 \mathrm{~N}$ (green line). The analysis also showed that highest load rates are present at rollers 10 to 14 during start-up time (2-5 seconds) and are equal to $800 \mathrm{~N}$. During subsequent simulation time, the cage was in contact with rollers only when the rollers were off-loaded and maximum force value was equal to $500 \mathrm{~N}$. Angular speed was constant $\left(489^{\circ} / \mathrm{s}\right)$ under applied roller load and lowered under roller load in the $20000 \mathrm{~N}$ to $70000 \mathrm{~N}$ range, achieving a minimum value of $435^{\circ}$ s (blue curve). 

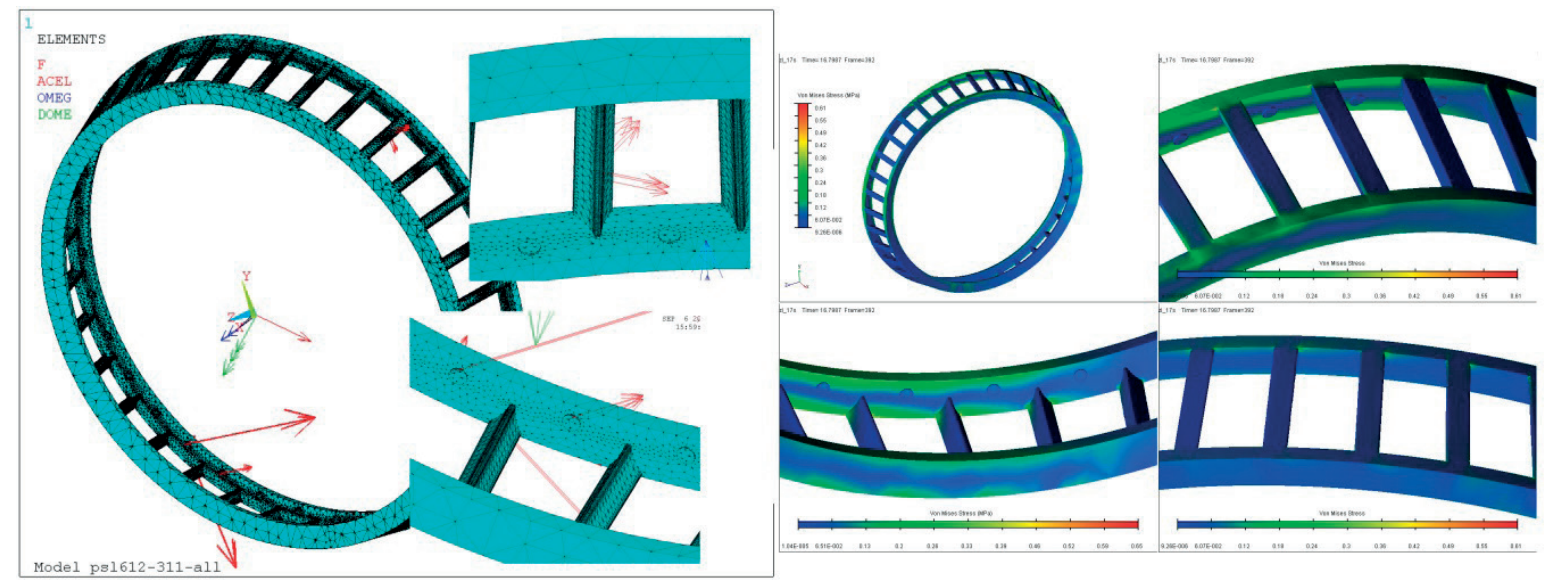

Fig. 7 Force interaction between plastic cage and rollers (left side) and maximum von Mises stress of plastic cage
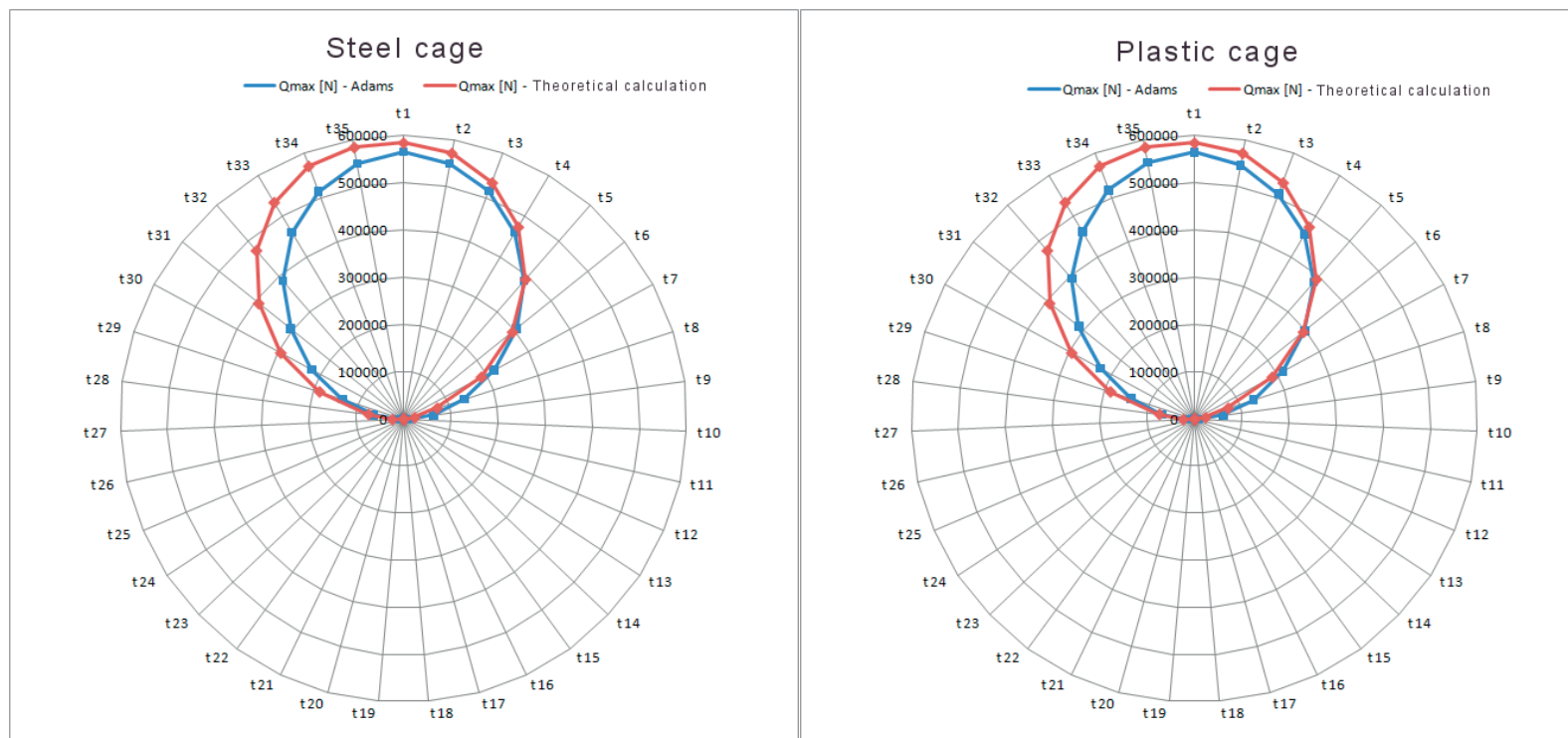

Fig. 8 Load distribution of individual elements compared with theoretical calculations

Figure 9 down shows force between inner ring and roller $\mathrm{n} .14$ (red line) for bearing with plastic cage. Maximum force between the plastic cage and rollers was observed for roller n.14 and is equal to $691 \mathrm{~N}$ (green line). Similar to the steel cage, highest load rates were present at rollers 10 to 14 during start-up time (2-5 seconds) and are equal to $700 \mathrm{~N}$. When compared to the steel cage, the rollers were in contact not only in the off-load phase (force equal to $150 \mathrm{~N}$ ) but also during the load phase, with the force equal to $400 \mathrm{~N}$. Angular speed was constant $\left(489^{\circ} / \mathrm{s}\right)$ under applied roller load and, similar to the steel cage, lowered under roller load in the $20000 \mathrm{~N}$ to $70000 \mathrm{~N}$ range, achieving a minimum value of $260^{\circ}$ /s (blue curve) and zero values under load.

Figure 10 shows the center of gravity location in the y-z plane of steel and plastic cage, Fig. 11 shows force interaction between inner ring and rollers and the von Mises stress of steel cage and
Fig. 12 shows force interaction between inner ring and rollers and the von Mises stress of plastic cage.

Analysis of dynamic simulation results shows the steel cage is in contact with rollers in lower and upper parts of the bearing, with forces in the upper bearing parts reaching up to $800 \mathrm{~N}$ at cage guides and $500 \mathrm{~N}$ at lower parts, also at cage guides. Maximum von Mises stress of $14.5 \mathrm{MPa}$ was recorded in time $\mathrm{t}=3.5 \mathrm{~s}$ (Fig. 11).

Dynamic simulation of plastic cage bearing shows similar results to those presented above. The plastic cage is in contact with rollers in lower and upper parts of the bearing. Forces in the lower part of the bearing reach up to $150 \mathrm{~N}$ at cage guides and up to $400 \mathrm{~N}$ at upper parts of the bearing cage guide surfaces. Maximum von Mises stress of $1.5 \mathrm{MPa}$ was recorded in time $\mathrm{t}=$ $9 \mathrm{~s}$ (Fig. 12). 

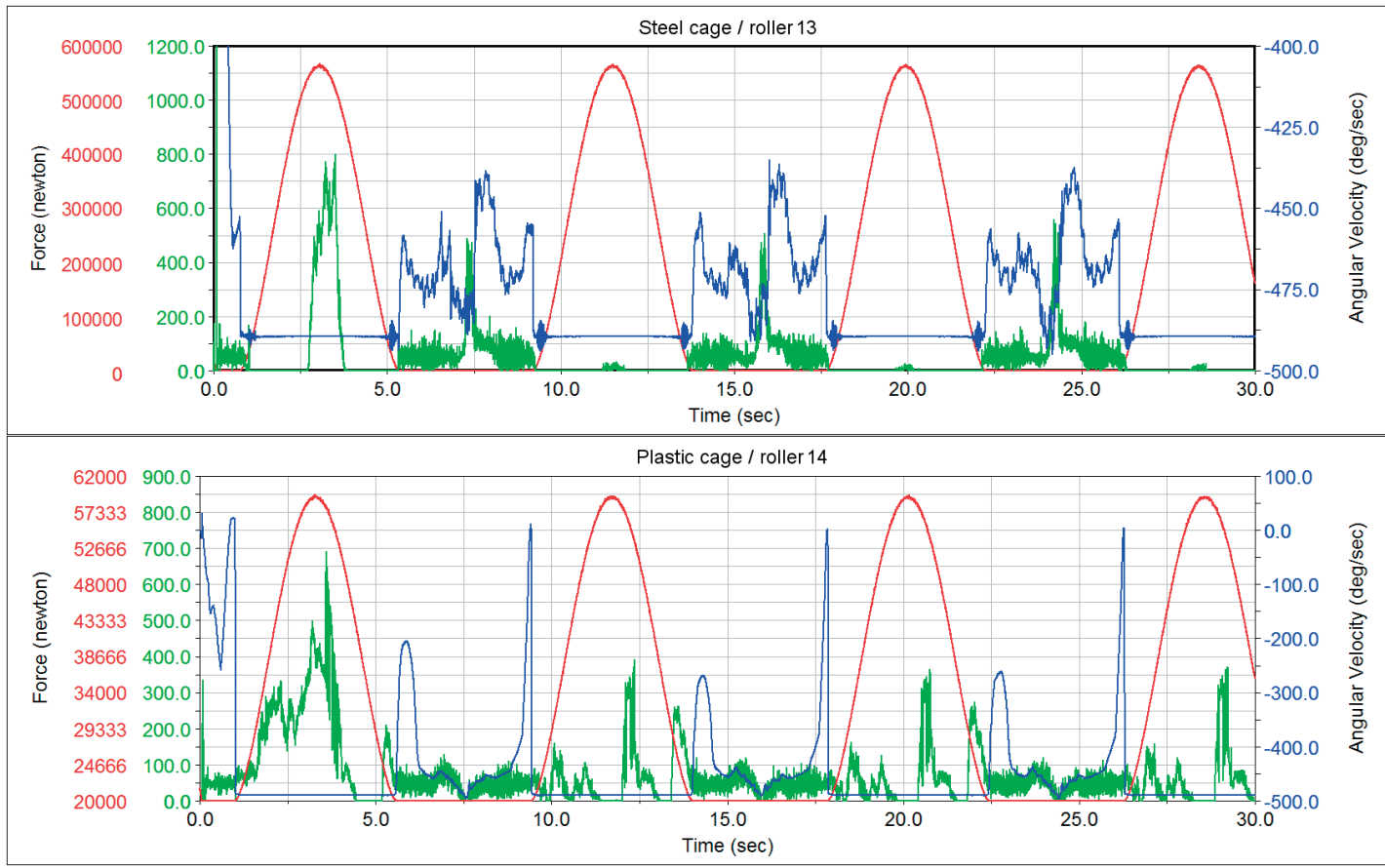

Fig. 9 Force interaction between inner ring and rollers (red lines), force interaction between cage and rollers (green lines), angular velocity of rollers (blue line)
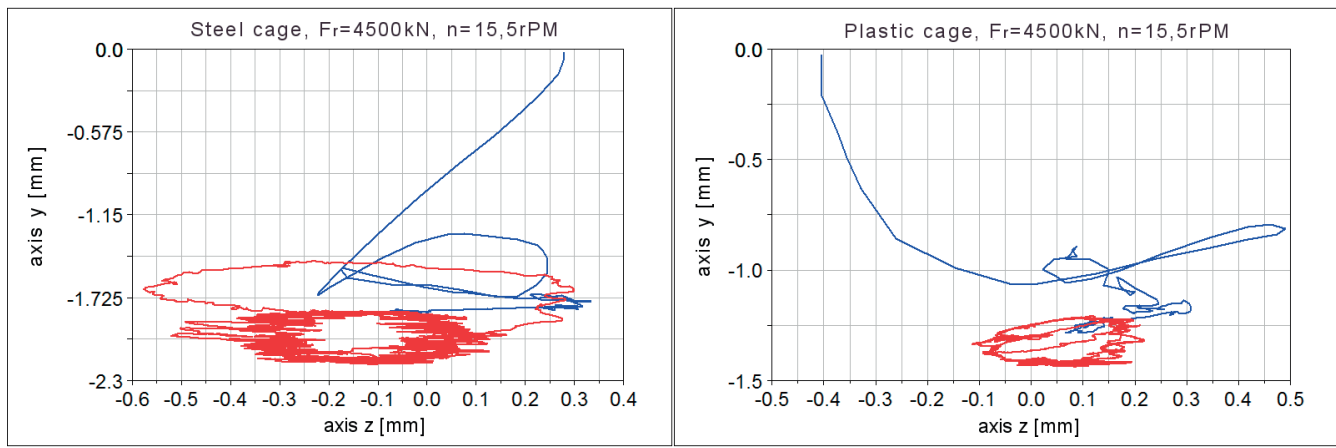

Fig. 10 Movement of center of gravity of steel cage (left side) and plastic cage (right side) in the $y$-z plane under axial load

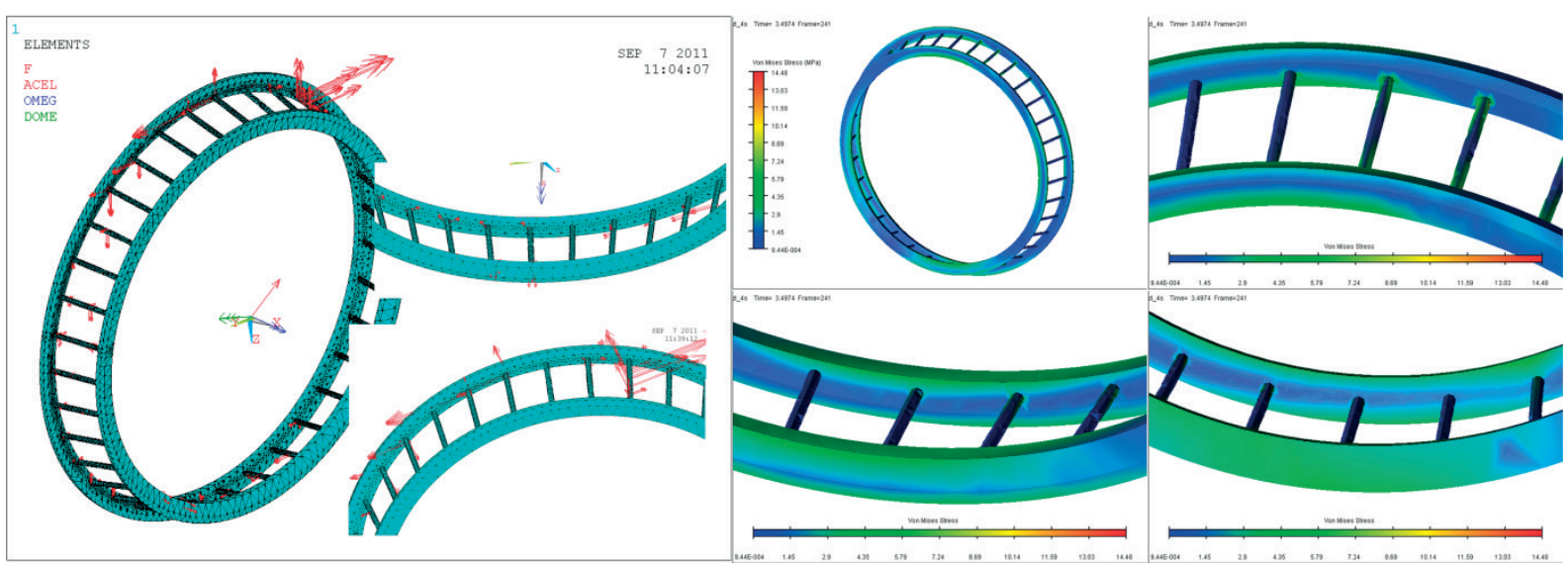

Fig. 11 Force interaction between steel cage and rollers (left side) and maximum von Mises stress of steel cage 


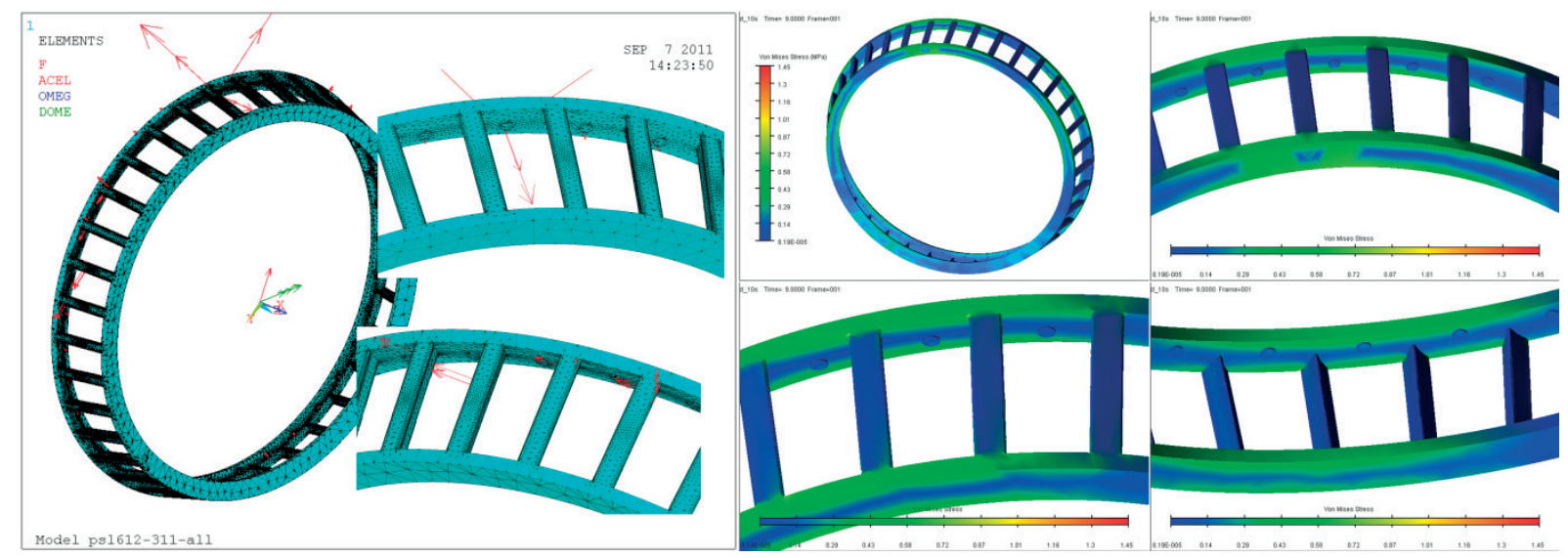

Fig. 12 Force interaction between plastic cage and rollers (left side) and maximum von Mises stress of plastic cage

\section{Conclusion}

The aim of this article was to detail with the creation of a tapered roller bearing model in the Adams software suite to be used for further dynamic analysis and to obtain information about individual parts during the simulation process taking into account the properties of the steel and plastic bearing cage for different load cases.

For axial load, dynamic analysis results show increased load variation of individual elements in steel cage when compared to the plastic cage, with a difference of $0.5 \%$ for minimum load for axial load. Minimal differences were observed under maximum loading conditions. Angular velocities of both analyzed cages shared similar waveforms. Analysis also shows that forces generated by interaction of rollers and plastic cage were 56\% lower when compared to the steel cage. Likewise, the overall plastic cage stress was an order of magnitude lower compared to the steel cage. The center of gravity of the plastic cage varied by $0.4-0.5 \mathrm{~mm}$ in all three axes when compared to the steel cage.

When applying radial force, we discovered that using plastic cage, the loading of rollers on offloaded side is lower when compared to steel cage. However, on the loaded side, the loading of rollers was higher when using a plastic cage. The analysis of the angular speeds rollers was found that at the time of loading, for both cages angular velocity does not change, the constant size of about $489^{\circ} . \mathrm{s}^{-1}$. Difference occurred at a time to reduce the load rollers when a steel cage changes randomly in the range of $436^{\circ} . \mathrm{s}^{-1}$ to $494^{\circ} \cdot \mathrm{s}^{-1}$. For a plastic cage, the course of the angular velocity was smoother, but compared to a steel cage, the rate decreased significantly and varied from $490^{\circ} . \mathrm{s}^{-1}$ to $0^{\circ} . \mathrm{s}^{-1}$. It was also found that the interaction force between the steel cage and the rollers occurred only at times of reduced loading rollers and it reached to $500 \mathrm{~N}$, which was $20 \%$ higher load than with a plastic cage. Plastic cage was received into contact throughout the course of the simulation, and the unloading rollers maximum load value amounted to $150 \mathrm{~N}$, the increase of load rollers, load increased to $400 \mathrm{~N}$. Variations in the rotation center of gravity for plastic cage were lower in all three axes as compared with a steel cage of 0.1 to 0.5 millimeters as opposed to the axial load.

The performed analyses have shown that the steel cage is more appropriate for axial loads, whereas the plastic cage is more suited for radial loads.

\section{References}

[1] KOHAR, R., MEDVECKY, S., HRCEK, S.: Usage of Dynamic Analysis to Determine Force Interactions between Components of Rolling Bearings with Different Rotation Speed. Machine Design, vol. 4, No. 3, 2012, 145-150, ISSN 1821-1259.

[2] RADEK, N., SLADEK, A., BRONCEK, J., BILSKA, I., SZCZOTOK, A.: Electrospark Alloying of Carbon Steel with WC-CoAl203: deposition technique and coating properties, Advanced Materials Research, vol. 874, 2014, 101-106, ISSN 1022-6680, (C) (2014) Trans Tech Publications, Switzerland, doi:10.4028/www.scientific.net/AMR. 874.

[3] BRONCEK, J., DZIMKO, M., HADZIMA, B., TAKEICHI, J.: Acta Metallurgica Slovaca, vol. 20, No. 1, 97-104, 2014. DOI 10.12776/ams.v20i1.273. 
[4] KUCERA, L., LUKAC, M., JURAK, L., BRUMERCIK, F.: Hydromechanical Automatic Transmission, Communications Scientific Letters of the University of Zilina, vol. 11, No. 2, 2009, 33-35.

[5] BRUMERCIK, F., KOCUR, R., PAZICAN, M., LUKAC, M.: Differential Hydro-mechanical Transmissions with Hydrostatic Units, Communications - Scientific Letters of the University of Zilina, vol. 7, No. 1, 2005, 49-53.

[6] DEKYS, V., BRONCEK, J.: Measuring Strain of the Latice Towers, Communications - Scientific Letters of the University of Zilina, vol. 14, No. 3, 2012, 39-42.

[7] BRONCEK, J., DZIMKO, M., HADZIMA, B., TAKEICHI, Y.: Experimental Investigations of Aluminium Alloys, 2024, T3 Form in Terms of Tribocorrosion Characteristics, Communications - Scientific Letters of the University of Zilina, vol. 20, No. 1, 2014, 97-104.

[8] SOARES, D. JR., SLADEK, V., SLADEK, J., ZMINDAK, M., MEDVECKY, S.: Porous Media Analysis by Modified MLPG Formulations, Computers, Materials and Continua, vol. 27, No, 2, 2012, 101-126.

[9] GREGOR, M., MEDVECKY, S.: Zilina University Concept of Digital Factory, Communications - Scientific Letters of the University of Zilina, vol. 10, No. 2, 2008, 60-66.

[10] MD Adams 2011 Online Help.

[11] HARRIS, T. A., KOTZALAS, M. N.: Essential Concepts of Bearing Technology, $5^{\text {th }}$ edition, 2007.

[12] FROHLICH, J.: Bearing Applications with Rolling Bearing, (in Slovak), Nakladatelství technické literatury : Praha, 1980. 